\title{
Mould Characterization and Mycotoxin Quantification of Chia Seeds (Salvia hispanica L.) Grown in Kenya
}

\author{
Veronicah Njeri ${ }^{1}$, Monica Mburu ${ }^{1}, \&$ Kipkorir Koskei ${ }^{1}$ \\ ${ }^{1}$ Institute of Food Bioresources Technology, Dedan Kimathi University of Technology, Nyeri, Kenya \\ Correspondence: Veronicah Njeri, Dedan Kimathi University of Technology, P.O Box Private bag, Nyeri, Kenya. \\ Tel: 254-718-458-186. E-mail: njeri.veroh87@gmail.com
}

Received: October 1, 2019

Accepted: October 17, 2019 Online Published: October 30, 2019

doi:10.5539/jfr.v8n6p119

URL: https://doi.org/10.5539/jfr.v8n6p119

\begin{abstract}
Chia seeds are functional food that have been considered highly nutritious. They have high levels of polyunsaturated fatty acid content therefore counteract lifestyle disorder such as cardiovascular diseases. This study sought to determine the level of mould contamination in chia seeds; enumeration and characterization of the types of molds and quantification of mycotoxin level, for chia seeds grown and sold in Kenya. A complete randomized block design with triplicates was used in the study. Samples were collected at random from farmers and distributors in Nyeri, Nakuru, Busia and Trans Nzoia counties. Moulds species were isolated from PDA and MEA Medias and morphological characteristics was determined under X 40 magnification power. Mould counts were found to be between $1.33 \times 10^{3} \mathrm{cfu} / \mathrm{ml}$ to $2.67 \times 10^{3} \mathrm{cfu} / \mathrm{ml}$. Mould characterization done by microscopic and macroscopic technique showed evidence of Rhizopus spp, Trichoderma spp and Fusarium spp. Amongst the three genera found, Rhizopus spp was the predominantly occurring mould. The percentage moisture content of chia seeds samples ranged from $6.49 \pm 1.26$ and $9.16 \pm 0.43$. Significant variations on moisture content $(p<0.05)$ were observed among chia samples from different farmers. Aflatoxin was not detected in all chia samples. It can therefore be concluded that the chia samples were not contaminated with aflatoxin although different species of mold were present. Farmers need to be trained on proper postharvest handling methods of chia seeds, as well as proper storage and an objective method of analyzing the moisture content of the chia seeds need to be developed.
\end{abstract}

Keywords: chia seeds, mould characterization, mycotoxins

\section{Practical Application}

This research will provide information on the levels of moulds and mycotoxin contamination in chia seeds which will be used for extension services geared towards training of farmers and chia seeds handlers on proper postharvest handling techniques by researchers and relevant bodies in achieving food security, improved nutrition, promotion of sustainable agriculture and addressing factors related to chia seeds contamination.

\section{Introduction}

Chia plant is a hardy annual herbecoues species that grows 1- 1.5 meters high. Taxonomically, it belongs to the Kingdom Plantae, order Lamiales, Labiatae family and Genus Salvia. Its name is derived from the Latin word 'Salare' which means to save; referring to its curative abilities, being a source of energy and stamina thus the vital reason why it was used by the Aztec and Mayan warriors of old Mexico during Pre-Columbian times (Ayerza and Coates, 2009). In the plant native habitat of South West America, it has been highly valued as a staple food for hundreds of years. Chia is currently grown in Bolivia, Mexico, Peru, Argentina with emphasis on the Salta, Jujuy, Tucuman and Catamarca (Busilacchi et. al, 2013). In Kenya, Chia growing has gained momentum because of its nutrition benefits thus it is grown in most counties such as Busia, Nakuru, Trans Nzoia, Machakos and Nyeri counties. Its wide applicationis because of the hardy properties in that chia seeds can withstand different kinds of climatic conditions.

The growing concern in the modern society to have a healthy diet has contributed to the increase in demand for foods that are rich in nutrients, containing beneficial substance to humans. Chia seeds are edible and rich source of essential nutrients, including proteins, antioxidant, fibre, polyunsaturated fatty acids like alpha-linolenic and linoleic acids (Menga et. al, 2017). They offer five times more calcium than milk and the enzymes in the seed aid in digestion.(Yao et.al, 2012) Polyunsaturated fatty acid are of great interest because it supports immune 
functions, inhibit the proliferation of inflammatory lymphocytes and cytokines, act to prevent the incidence of cardio vascular diseases and maintain the integrity of cell membrane and neurotransmitters (Ludwig et. al, 2013). They are considered safe as they do not have gluten and toxic compounds thus making the seeds a safe ingredient for gluten free diets (Menga et. al, 2017). Studies done by Ayerza in 2013, shows that for the chia seed types commercilaized today, the coat colour is either black or white and there is no chemical composition difference.

A major challenge with agricultural crops is contamination with moulds due to poor handling and storage. Moulds growth lead to production of mycotoxins such as aflatoxins, Ochratoxins A, fumonisins, deoxynivalenol, T-2 toxin and zearalenone (Proctor et. al, 2009). These mycotoxins have been associated with a wide range of adverse and toxic effects in humans like liver cancer, thus classified as foodborne hazards. Regulations for major mycotoxins across different food and feed and their maximum tolerated levels are documented. For instance, importation of chia seeds to the European countries require stringent maximum tolerable limits so that it is allowed in their market. Similar chia studies done in Argentina have shown that chia seeds can be contaminated with aflatoxins (JEFCA, 2008).

\section{Materials and Methods}

\subsection{Treatments and Experimental Design}

A complete randomized block design with three replicates was used in sample collection from randomly selected farmers from Nyeri, Nakuru, Busia and Trans Nzoia counties. From each county three farmers were selected randomly and for every farmer, samples weighing 250 grams was collected from different locations in their stores and replicated three times. Samples were also collected from a major supermarket who operate as the main local distributor of chia seeds in Nyeri county.

The samples collected were put in sterile plastic bags, labelled and refrigerated at $8{ }^{\circ} \mathrm{C}$. The sample origin, date of harvesting, weight and sampling date were recorded.

\subsection{Study Site}

The samples were randomly drawn from different counties namely Trans Nzoia, Nakuru, Nyeri and Busia, which are known for chia seeds cultivation in Kenya and have different climatic conditions that affect the post-harvest handling methods and storage. A preliminary study was carried out to know how the different farmers and supermarkets handle chia seeds after harvesting.

\subsection{Preliminary Study}

\subsubsection{Determination of Post-harvest Handling Techniques}

Purposive sampling was used to administer survey questionnaire for the preliminary study to ascertain whether post-harvest handling techniques influenced chia mould contamination. Structured and open-ended questionnaires was administered to farmers and the main distributor to study the nature of post-harvest handling techniques employed. The study involved qualitative analysis of data where data cleaning was done to determine inaccurate, missing data and inconsistencies. Thematic and content analysis was employed in the analysis of this data taking on descriptive and analytical explanations.

\subsubsection{Determination of Moisture Content}

Moisture content of the chia seeds was determined according to AOAC (2000) method. Moisture dishes were washed and placed in an oven to dry at $105^{\circ} \mathrm{C}$ for one hour. The dishes were then cooled in a desiccator to room temperature. The initial weight of the dishes was taken using analytical balance and recorded as $\left(\mathrm{W}_{1}\right)$. Ground chia seeds sample of 5 grams was weighed in moisture dishes and weight recorded $\left(\mathrm{W}_{2}\right)$. The moisture dishes were then placed into an oven maintained at $105^{\circ} \mathrm{C}$ for two hours after which they were cooled in a desiccator to room temperature and weight taken. The dishes were returned to the oven for thirty minutes and weight taken. This was repeated until a constant weight is obtained $\left(\mathrm{W}_{3}\right)$. This was done in triplicates.

$$
\text { Moisture content }(\%)=\left(\mathrm{W}_{3}-\mathrm{W}_{1}\right) /\left(\mathrm{W}_{2}-\mathrm{W}_{1}\right) * 100
$$

\subsection{Mould Enumeration and Identification}

From each chia sample, $5 \mathrm{~g}$ of the seeds was taken. Isolation was performed by direct plating technique (Perrone et. al, 2007) where the seeds were applied on the surface of solidified Potato Dextrose Agar medium. The plates were then incubated at $25^{\circ} \mathrm{C}$ for five days. The colonies were then counted using a colony counter and expressed as $\mathrm{CFU} / \mathrm{ml}$ After incubation the plates were examined for colony growth visually. The suspected colonies of Aspergillus species were isolated by streaking in Malt Extract Agar (MEA) and incubated at $25^{\circ} \mathrm{C}$ for seven 
days.

Morphological analysis of Aspergillus was done by microscopic and macroscopic technique. Aspergillus ssp. was identified according to Samson et al., (2014) where the colony characters such as color and texture of the mycelium, characteristics of conidiophores such as shape of conidial heads, color of stipes were examined. Moulds were identified and characterized according to their unique morphological features.

\subsection{Screening for Mycotoxin (aflatoxin) Production}

\subsubsection{Aflatoxin Standards Solution Preparation and Analysis}

Stock standards of two milligrams Aflatoxins $B_{1}$ was dissolved in $100 \mathrm{ml}$ methanol to make $20 \mathrm{ppm} \mathrm{B}_{1}$ or 20000 ppb. Stock standards of one milligram of Aflatoxins $B_{2}$ and $G_{2}$ were dissolved in $100 \mathrm{ml}$ methanol to make 20 $\mathrm{ppm} \mathrm{B}_{1}$ or $10000 \mathrm{ppb}$. From stock above, five milliliters of each standard were pipetted to make $15 \mathrm{mls}$ combined standards which were evaporated under nitrogen. The resultant was reconstituted with twenty-five milliliter of acetonitrile. The resulting concentration was calculated as per (AOAC, 2000).

\subsubsection{Standard Derivatization}

Each standard solution was dried under a stream of nitrogen and $200 \mu \mathrm{l}$ hexane was added to dissolve aflatoxins in hexane. One hundred microliter of trifluoroacetic acid was added, mixed for five minutes. Two milliliters of Acetonitrile and water in the ratio of $\left(\mathrm{ACN}\right.$ : $\mathrm{DH}_{2} \mathrm{O}$ 10:90) was added and the aqueous layer filtered; and using $0.45 \mu \mathrm{m}$ inject into high performance liquid chromatography system.

\subsubsection{Sample Preparation According to LS Bates (with modifications)}

Fifty grams of the ground sample was weighed in triplicate and transferred into $250 \mathrm{ml}$ flask then added with 200 $\mathrm{ml} 80 \%$ methanol. The mixture was ultrasonicated for 2 minutes, filtered and pipetted where $100 \mathrm{mls}$ was transferred into $250 \mathrm{ml}$ conical flask. Eighty milliliters of $20 \%$ Ammonium sulphate was added and then more forty milliliters of hexane added to the mixture; then ultrasonicated for two minutes. This was then drained, and the lower layer saved and transferred into a $200 \mathrm{ml}$ separating funnel. Six milliliter of methylene chloride was added and shook vigorously, then collected. Four milliliter of methylene chloride (chloroform) was added and shook vigorously to combine the two layers and a five milliliter of the solution was pipetted for clean-up and a further five milliliter preserved in the deep freeze at $8{ }^{\circ} \mathrm{C}$.

\subsubsection{Column Preparation}

Eight grams of sodium sulphate $\left(\mathrm{Na}_{2} \mathrm{SO}_{4}\right)$ was added to a $22 \mathrm{X} 400 \mathrm{~mm}$ chromatographic tube to give base for silica gel. Chloroform was then added up to $3 / 4$ of the column. Ten grams of the activated gel was added.

Activating silica gel was prepared by weighing about 200 grams silica gel of size 0.04 . The silica gel was then put in oven for one hour set at $105^{\circ} \mathrm{c}$. Two milliliters of distilled water were then added and shaken thoroughly to mix. Silica gel was then stored in an airtight container for more than fifteen hours. After addition of activated silica gel the column was left to settle for thirty minutes. Chloroform was then drawn until it was just above silica gel. Fifteen grams of the silica gel was added to the column and five milliliters of filtrate was added to column. Fifty milliliter of $n$ hexane was added to the column and drawn to just above anhydrous sodium sulphate in order to remove pigments. Twenty milliliter of diethyl ether was added and drawn for the level to be just above that of anhydrous sulphate to remove fats and oils. Twenty milliliters of methanol: chloroform (3:97) mixture was then added in order to elute the toxins.

\subsubsection{Sample Derivatization}

Each of the sample was dried under a stream of nitrogen and two hundred microliters of hexane added to dissolve aflatoxins. One hundred microliter of trifluoroacetic acid was added to the mixture which settled for five minutes. Two milliliters of Acetonitrile and distilled water (10:90) was added to the mixture and the aqueous layer filtered; and from the mixture $0.45 \mu \mathrm{m}$ was injected into the reverse phase high performance liquid chromatography system.

\subsubsection{Spiking}

Fifty grams of the ground sample was weighed in triplicate and transferred into a $250 \mathrm{ml}$ conical flask. In the flask, $200 \mathrm{ml}$ of $80 \%$ methanol and $600 \mu \mathrm{l}$ aflatoxin $\mathrm{B}_{1}$ of $24 \mathrm{ppm}$ and $800 \mu \mathrm{l} 16 \mathrm{ppm} \mathrm{B}_{2}$ and $\mathrm{G}_{2}$ were added in the sequence as stated. The mixture was ultrasonicated for two minutes, then one hundred milliliters was filtered and pipetted and transferred to a $250 \mathrm{ml}$ conical flask where $80 \mathrm{ml} 20 \%$ Ammonium sulphate was added followed by addition of $40 \mathrm{mls}$ hexane and ultrasonication for two minutes. It was then drained, and the lower layer was saved and transferred into a $200 \mathrm{ml}$ separating funnel $6 \mathrm{ml}$ of methylene chloride was added. This was then 
shaken vigorously and the lower layer of Methylene Chloride (Chloroform) was collected. The two layers were then combined and shaken vigorously, and a five milliliter was pipetted for clean-up whereas another five milliliters was preserved in the deep freezer.

\subsection{Data Analysis}

SPSS Version 23 with Duncan test program software was used for statistical analysis and results was presented as mean $\pm \mathrm{SD}$. Comparison of the mean difference was done by one-way analysis of variance (ANOVA) and significance differences between the means was established at $\mathrm{p}<0.05$. Data was presented using graphs and tables.

\section{Results and Discussion}

\subsection{Preliminary Study}

\subsubsection{Post-harvest Handling Techniques and Moisture Content (\%)}

The results for the moisture content for the samples from different farmers are presented in Table 1. The percentage moisture content for the chia samples ranged between $6.49 \pm 1.26$ and $9.16 \pm 0.43$. This was within the range reported by authors who did similar studies on flax seeds and chia seeds which had a range of 6- 8 (FAO, 2015) There were significant variations in the moisture content of the samples obtained from the different farmers. This could be attributed to lack of a standard method which farmers can use in the determination of moisture content level. From the preliminary study done, most of the chia farmers use traditional methods where they either chewed, touched or looking to determine if the chia seeds are dry. The counties where samples were collected have different climatic conditions and how they dry the chia seeds and the amount of exposure time to the sun during drying could also lead to the difference in moisture content between the samples from different counties.

Table 1. Moisture content analysis of means with Duncan test of samples from different counties

\begin{tabular}{|c|c|c|c|c|c|c|c|c|}
\hline \multirow[t]{2}{*}{ Sample Area } & \multirow[t]{2}{*}{$\begin{array}{l}\text { Sample } \\
\text { description }\end{array}$} & \multirow[t]{2}{*}{$\mathrm{N}$} & \multirow[t]{2}{*}{$\begin{array}{l}\% \text { Moisture } \\
\text { content }\end{array}$} & \multirow[t]{2}{*}{$\begin{array}{l}\text { Standard } \\
\text { Error }\end{array}$} & \multicolumn{2}{|c|}{$\begin{array}{l}95 \% \text { Confidence } \\
\text { Interval for Mean }\end{array}$} & \multirow[t]{2}{*}{$\begin{array}{l}\text { Minimum } \\
\text { Level }\end{array}$} & \multirow[t]{2}{*}{$\begin{array}{l}\text { Maximum } \\
\text { Level }\end{array}$} \\
\hline & & & & & $\begin{array}{l}\text { Lower } \\
\text { Bound }\end{array}$ & $\begin{array}{l}\text { Upper } \\
\text { Bound }\end{array}$ & & \\
\hline 1.Naivas & 100A1 & 3 & $9.06 \pm 0.41^{\mathrm{a}}$ & 0.03 & 8.69 & 9.43 & 9.04 & 9.09 \\
\hline \multirow[t]{3}{*}{ Supermarket } & 100B1 & 3 & $9.16 \pm 0.43^{b}$ & 0.24 & 9.05 & 9.27 & 9.12 & 9.20 \\
\hline & $100 \mathrm{C} 1$ & 3 & $9.04 \pm 0.02^{\mathrm{a}}$ & 0.01 & 9.00 & 9.07 & 9.02 & 9.05 \\
\hline & Total & 9 & $9.09 \pm 0.07^{\mathrm{a}}$ & 0.02 & 9.03 & 9.15 & 9.02 & 9.30 \\
\hline \multirow[t]{5}{*}{ 2.Nyeri } & $101 \mathrm{~A} 1$ & 3 & $8.02 \pm 0.01^{\mathrm{a}}$ & 0.01 & 7.92 & 8.12 & 8.01 & 8.03 \\
\hline & 101B1 & 3 & $7.92 \pm 0.02^{\mathrm{a}}$ & 0.01 & 7.90 & 7.94 & 7.91 & 7.93 \\
\hline & $101 \mathrm{C} 1$ & 3 & $7.81 \pm 0.06^{\mathrm{a}}$ & 0.04 & 7.66 & 7.97 & 7.76 & 7.88 \\
\hline & Total & 9 & $7.91 \pm 0.09^{\mathrm{a}}$ & 0.03 & 7.83 & 7.98 & 7.76 & 8.03 \\
\hline & $102 \mathrm{~A} 1$ & 3 & $7.88 \pm 0.02^{\mathrm{a}}$ & 0.02 & 7.69 & 8.07 & 7.87 & 7.90 \\
\hline \multirow[t]{3}{*}{ 3. Nakuru } & 102B1 & 3 & $6.49 \pm 1.26^{\mathrm{c}}$ & 0.73 & 3.35 & 9.63 & 5.10 & 7.57 \\
\hline & $102 \mathrm{C} 1$ & 3 & $7.91 \pm 0.03^{\mathrm{a}}$ & 0.02 & 7.83 & 7.99 & 7.88 & 7.94 \\
\hline & Total & 9 & $7.36 \pm 0.99^{c}$ & 0.35 & 6.54 & 8.20 & 5.10 & 7.94 \\
\hline \multirow[t]{4}{*}{ 4.Trans Nzoia } & $103 \mathrm{~A} 1$ & 3 & $8.36 \pm 0.00^{\mathrm{a}}$ & 0.00 & 8.35 & 8.37 & 8.36 & 8.36 \\
\hline & 103B1 & 3 & $8.37 \pm 0.02^{\mathrm{a}}$ & 0.01 & 8.32 & 8.43 & 8.35 & 8.39 \\
\hline & $100 \mathrm{C} 1$ & 3 & $8.33 \pm 0.01^{\mathrm{a}}$ & 0.01 & 8.31 & 8.36 & 8.32 & 8.34 \\
\hline & Total & 9 & $8.36 \pm 0.02^{\mathrm{a}}$ & 0.01 & 8.33 & 8.38 & 8.32 & 8.39 \\
\hline \multirow[t]{4}{*}{ 5. Busia } & $104 \mathrm{~A} 1$ & 3 & $9.11 \pm 0.08^{\mathrm{a}}$ & 0.03 & 8.69 & 9.33 & 9.04 & 9.09 \\
\hline & 104B1 & 3 & $9.15 \pm 0.23^{b}$ & 0.14 & 9.02 & 9.27 & 9.12 & 9.21 \\
\hline & $104 \mathrm{C} 1$ & 3 & $9.08 \pm 0.0^{\mathrm{a}}$ & 0.01 & 9.00 & 9.17 & 9.02 & 9.05 \\
\hline & Total & 9 & $9.11 \pm 0.04^{\mathrm{a}}$ & 0.01 & 9.05 & 9.16 & 9.02 & 9.20 \\
\hline
\end{tabular}

All values are mean values of triplicates \pm standard deviations. Values in the same column with different letters are significantly different $(\mathrm{p}<0.05)$ by Duncan test.

It is important to get the timing right for harvesting as in the preliminary studies it was observed that farmers have different ways of noting that the time for harvesting is ready. The farmers look at the change of flower colors which was like studies done on ground nuts where the color change $f$ petals denoted that the plant was ready for harvesting. If the seeds are harvested too early, then the seeds will shrink and may lower the oil content 
and quality of the seed. If the seeds are delayed at the farm, then chia seeds may drop on the ground leading to yield losses and poor-quality seeds due to mould infection

\subsection{Mould Characterization and Enumeration}

The results for moulds levels in the samples from different counties are presented in Table 2. In the analysis, different types of moulds were identified which includes; Fusaruim spp, Rhizopus spp, Alternaria spp and Trichoderma spp. From the results, it was observed that the county that had the most mould contamination of chia seeds is Nyeri county with the highest levels of Fusarium and Rhizopus species. The county with the lowest level of mould contamination is From the results, the county with the lowest level of mold conatmination is Busia county. This could be deduced from the fact that the climatic conditions in Nyeri county are very humid and the mold growth is accelerated in such conditions while in Busia has dry and hot climatic conditions that do not favour mould growth and mould contamination.. The most predominant mould species according to the result was observed to be Rhizopus species. This is similar to the studies done by Rifai (1969) which indicated that Rhizopus spp are very common in soil and air. The acceleration of mould growth is favoured by the humid conditions, nutrients for the fungi and also poor post harvest handling techniques (USAID, 2012). From the preliminary studies indicated in the appendix, it is observed that farmers in the sampled counties spread the chia seeds on a gunny bag to dry on the sun. There are many types of fungi that are found in soil and air that could contaminate the chia seeds. The accelerating factor is that the climatic conditions in Nyeri county favoured even more fungi to be present in the chia seeds.

Table 2. Mould enumeration in the sampled chia seeds from different counties

\begin{tabular}{llllll}
\hline Mould Type & Busia & Nyeri & Naivas & Nakuru & Trans Nzoia \\
\hline Fusarium & 333.33 & 1333.33 & 333.33 & 1000 & 1000 \\
Alternaria & 0 & 333.33 & 333.33 & 333.33 & 333.33 \\
Trichoderma & 0 & 666.67 & 0 & 0 & 333.33 \\
Rhizopus & 1333.33 & 2666.67 & 1333.33 & 1333.33 & 2000 \\
\hline
\end{tabular}

Upon observing the petri dishes macroscopically, chia sprouts were observed in a number of the petri dishes confirmimg that the chia seeds were not dry enough. Further moulds observation macroscopically and microscopically, it was evident that colonies of predominant fungal species of Rhizopus were identified positively. The county with the most fungal growth was observed to be Nyeri county and the least was observed to be Busia county. This can be deduced from the fact that the humid climatic conditions in Nyeri favoured the mold growth unlike the hot and dry conditions in Busia county. Across all counties, Rhizopus spp was evidently present than any other species. Trichoderma spp was less predominant and this could be because they are not commonly occuring moulds.

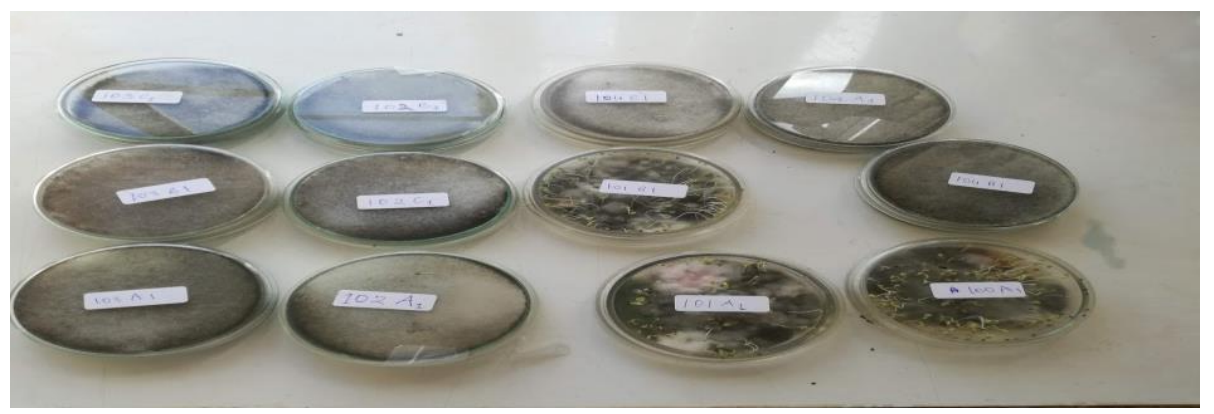

Figure 1. Picture of macroscopical characters of the fungal growth observed on potato dextrose agar media

Chia sprouts could be growing in diferent petri plates as an indication that the chia seeds contained higher moisture content.This is evident in the preliminary study as the farmers do not have an objective way of determining whether the chia seeds are dry enough. The results were similar to the study done in Uganda for post harvest losses in grains that denoted that farmers in Uganda did not have an objective way of determinging dryness of grains and so when they processed, it resulted to yield losses (USAID, 2012). 

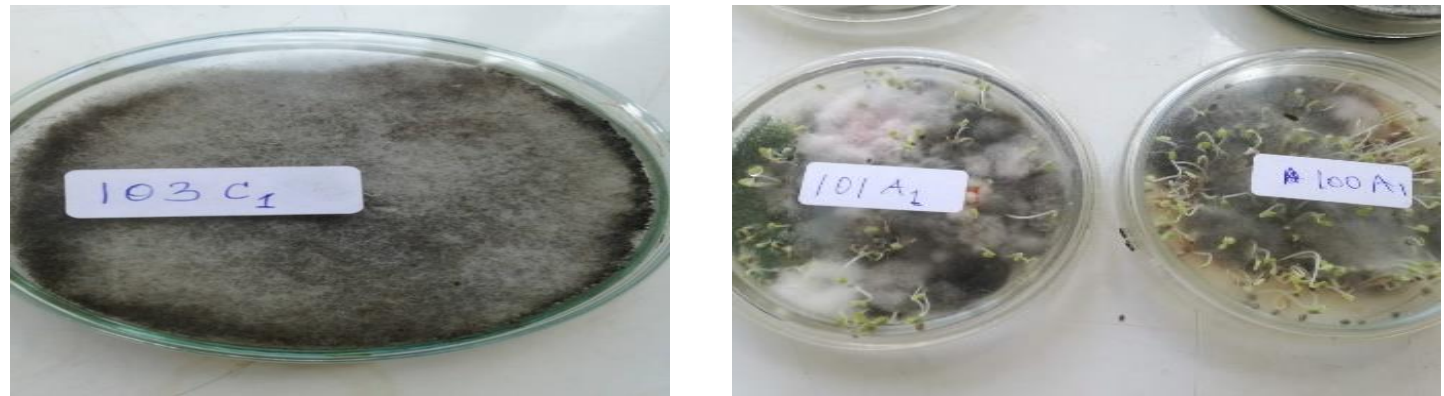

Figure 2. Colonies of Rhizopus spp and chia sprouts observed macroscopically

\subsubsection{Morphological Description of Identified Moulds Species}

Morphological analysis was done by microscopic and macroscopic technique according to Samson et. al, (2014) where the colony characters such as color and texture of the mycelium, characteristics of conidiophores such as shape of conidial heads, color of stipes were examined. Moulds were identified and characterized according to their unique morphological features where a drop of methylene blue was added to the slide and cover slip put on top where observation was done under a light microscope at magnification X40.

From the results, different molds types were observed macroscopically as shown in the photos of the petri plates above. Upon transferring the molds to MEA, the different mould species were noted and macroscopically identified.

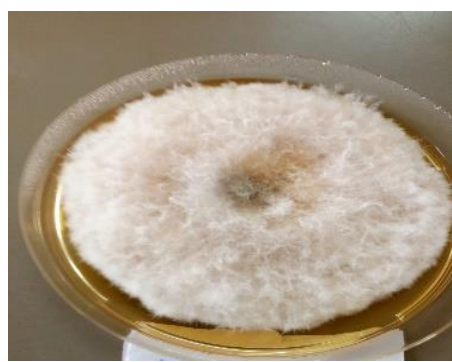

Fusarium spp

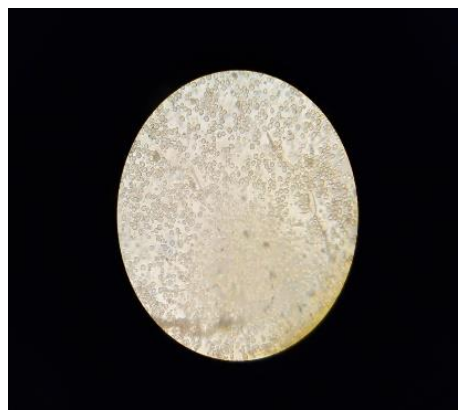

Figure 3. Picture of microscopical characters of the different type of molds as seen under a light microscope of X40 magnification

\subsection{Aflatoxin Analysis Quantification}

The results for aflatoxin quantification are presented in Table 3. From the analysis, there were no aflatoxins detected in the samples from all the counties. The stock solution of the prepared standards Aflatoxin $B_{1}, G_{1}$ and $\mathrm{G}_{2}$, were used in the analysis and the results for all the samples did not match any of this aflatoxin standards. 
Table 3. Aflatoxin quantification analysis of the chia seeds samples of farmers from different counties

\begin{tabular}{llll}
\hline Counties & Samples & Aflatoxin B1 & Aflatoxin G1 and G2 \\
\hline Busia & Farmer 1 & Not Detected & Not Detected \\
& Farmer 2 & Not Detected & Not Detected \\
& Farmer 3 & Not Detected & Not Detected \\
Nyeri & Farmer 1 & Not Detected & Not Detected \\
& Farmer 2 & Not Detected & Not Detected \\
& Farmer 3 & Not Detected & Not Detected \\
Naivas & Farmer 1 & Not Detected & Not Detected \\
& Farmer 2 & Not Detected & Not Detected \\
& Farmer 3 & Not Detected & Not Detected \\
Nakuru & Farmer 1 & Not Detected & Not Detected \\
& Farmer 2 & Not Detected & Not Detected \\
& Farmer 3 & Not Detected & Not Detected \\
Trans Nzoia & Farmer 1 & Not Detected & Not Detected \\
& Farmer 2 & Not Detected & Not Detected \\
& Farmer 3 & Not Detected & Not Detected \\
\hline
\end{tabular}

Upon subjecting the samples to the high-performance liquid chromatography for mycotoxin quantification, the following chromatograms were observed. The aflatoxin standard was derived from the stock solution and prepared for reverse phase high-performance liquid chromatography where upon injection, the chromatogram $1 \mathrm{~A}$ below was observed.

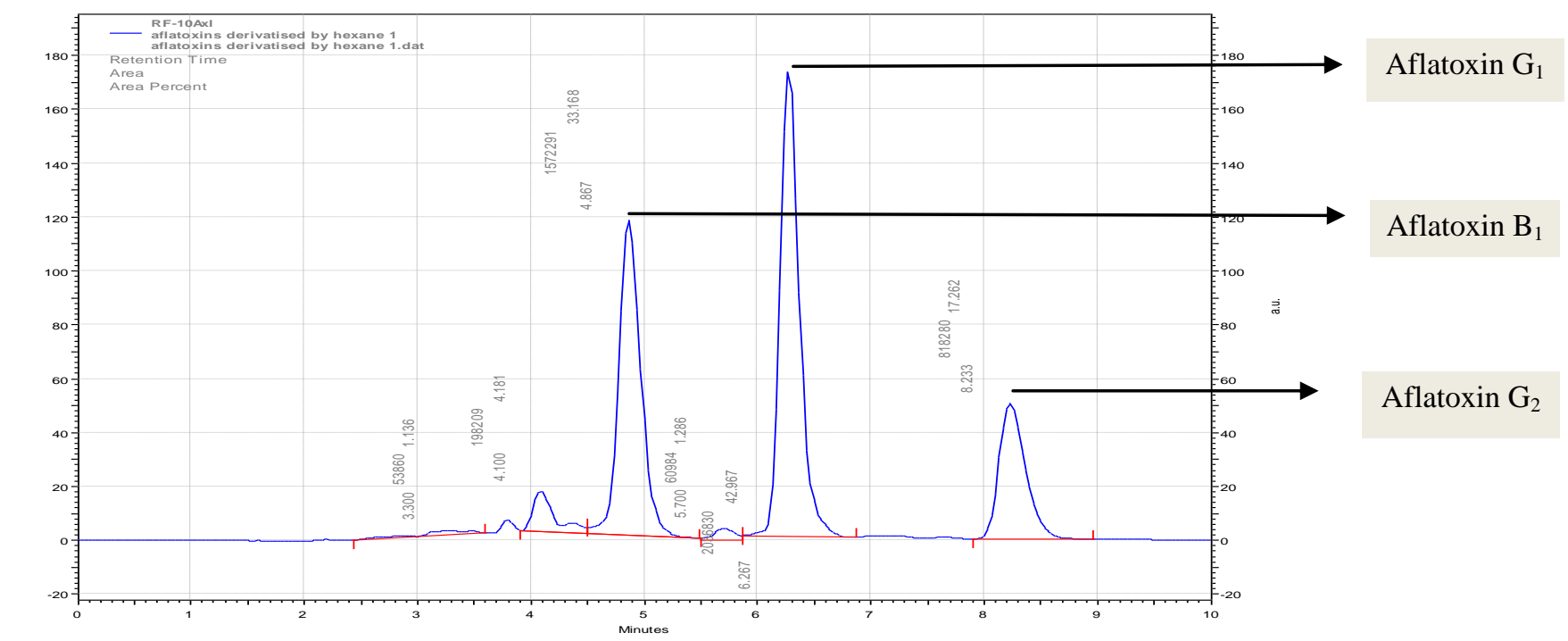

Figure 4. Chromatogram for the standards aflatoxin solution upon injecting into the high-performance liquid chromatography

The chromatogram below depicts the standard solutions chromatogram where they were overlaid as shown in the below chromatogram to indicate the mycotoxins of interest for ease of identification. 


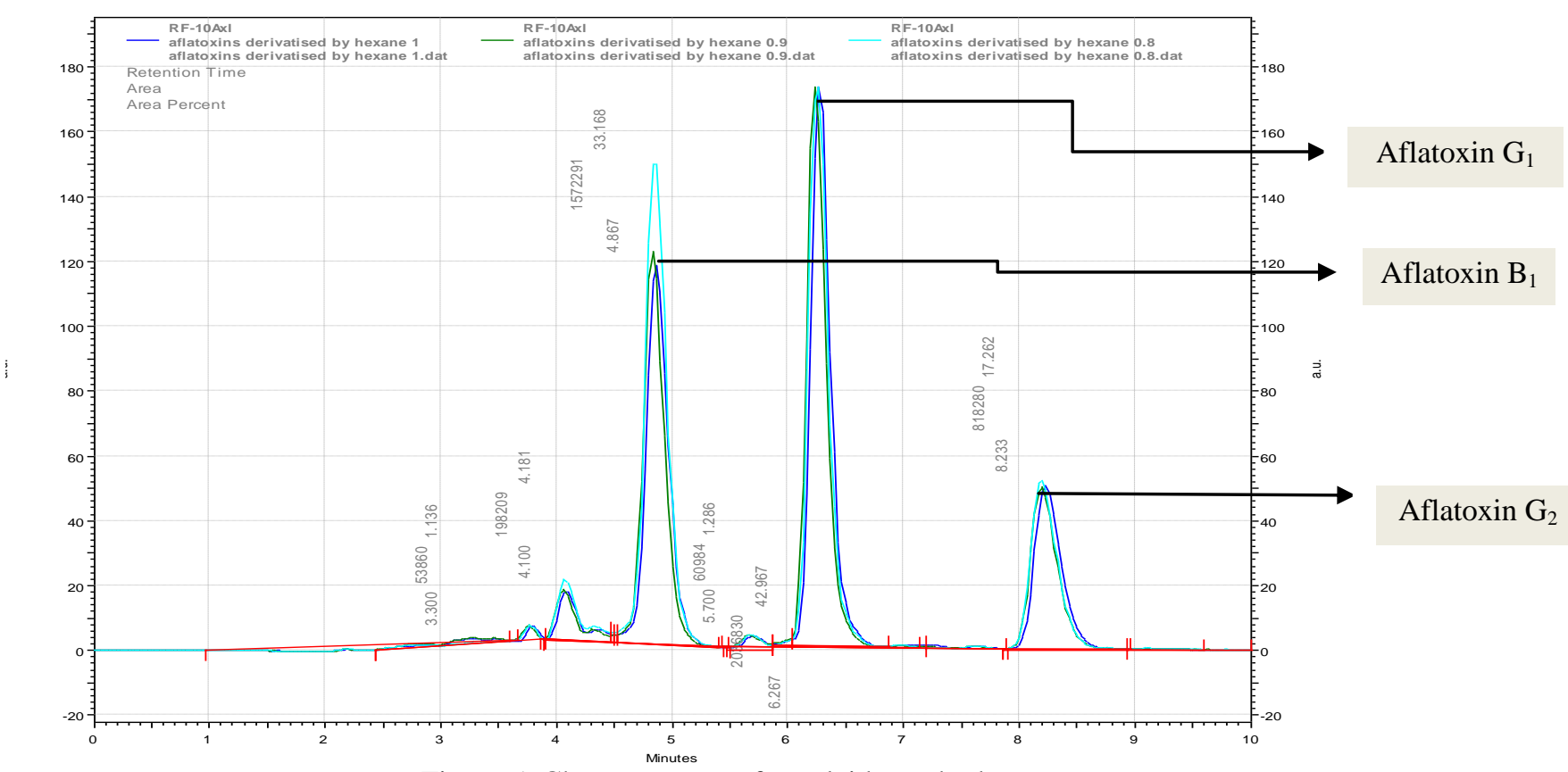

Figure 5. Chromatogram of overlaid standards

The chromatogram in figure 6 indicates that no mycotoxin of interest was present, and this was counterchecked by spiking the sample to check for accuracy. Quality assurance for the data was also done to ensure that the $\mathrm{R}^{2-}$ was correct. The chromatogram attached in the appendix also shows that no aflatoxin of interest was observed in the chia seed sampled from the farmers in the different counties. Spiking was done to countercheck the methodology was correct and that the findings observed were true and correct.

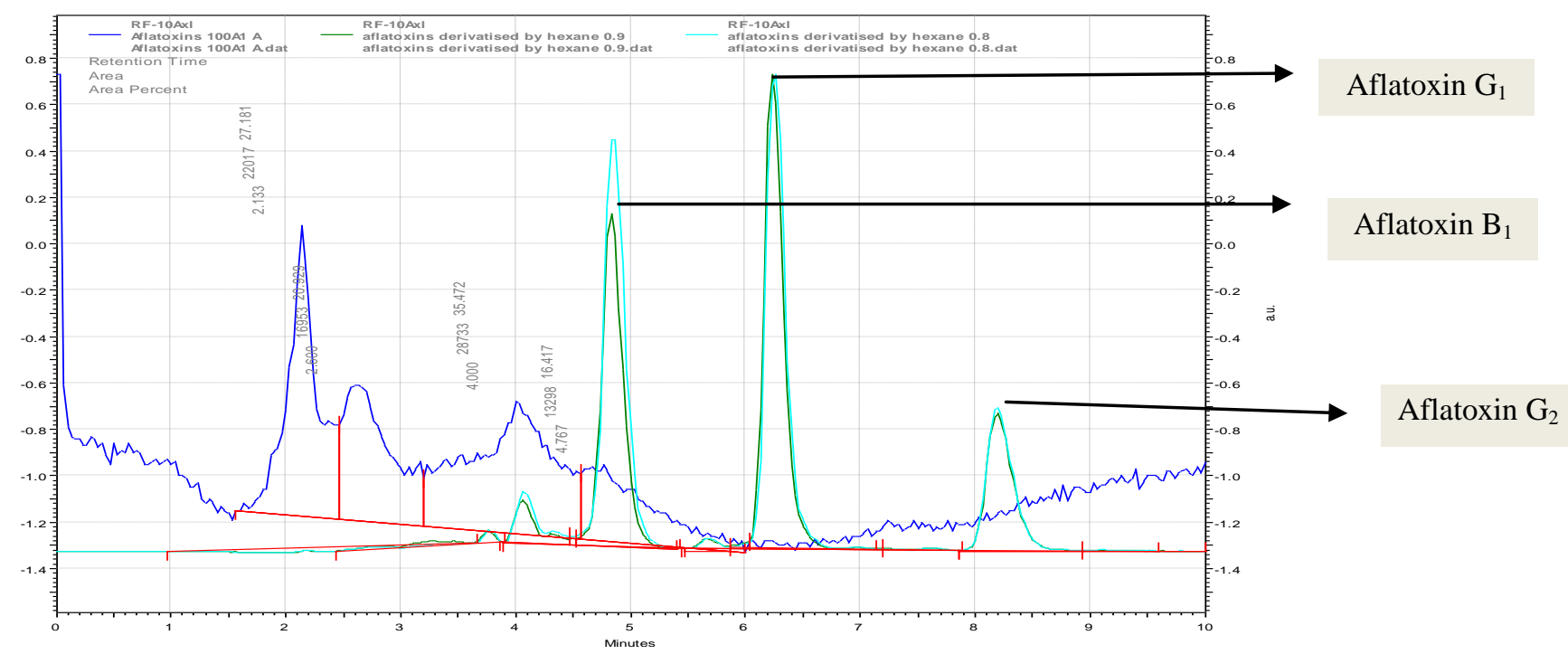

Figure 6. Sample chromatogram of the chia seeds aflatoxin analysis

\section{Conclusion}

From the preliminary study, as much as the different farmers have been trained on proper post-harvest handling techniques, modern technology needs to be employed in handling chia seeds post-harvest to reduce losses. This will reduce the manual handling and gut feeling from different farmers when determining the dryness of the chia seed to employ better shelling and winnowing technologies and separation of the chia seeds from the trash. The chia seeds purity level, moisture content, lack of damaged or diseased seeds play a great role in determining the 
grade of the chia seeds and thus its price. The better the grade, the better the price and more revenue to the farmers.

The findings indicate that chia seeds from different farmers have different moisture content levels and thus an objective method of determining dryness of the seed should be developed and communicated to all chia seed farmers for standardization purposes. This will ensure that the moisture content is optimum and will not favor mould contamination no matter the climatic conditions. Grading of chia seeds should also be objectively done for standardization purposes through ascertaining scientifically the level of purity, moisture level and absence of diseases and aflatoxins.

Sampled chia seeds from different farmers did not have aflatoxin contamination although mould contamination was noted. Just as the European union has set a guideline on the thresholds of Aflatoxin maximum allowable limits, the government needs to put in policy for the maximum permissible threshold for mould contamination because most of these mould cause allergic reaction and mycotoxicosis in humans upon exposure or ingestion.

\section{Acknowledgments}

This study was carried out at the Institute of Food Bioresources Technology, Dedan Kimathi University of Technology, supported by the National Research Fund, Kenya.

\section{Conflicts of Interest}

The authors declare no conflict of interest.

\section{Compliance with Ethics Requirements}

This article does not contain any studies with human or animal subjects.

\section{References}

Abarca, M. L., Bragulat, M. R., Castell, G., \& Kabanes, F. J. (2006). Mycoflora and aflatoxins producing strains in chia seeds. Journal of Food Protection, 57(3), 256-258. https://doi.org/10.4315/0362-028X-57.3.256

Ali, M. A., Soad, A., \& Hosny, A. L. (2005). Quantitative, qualitative and toxigenic evaluations of mold in Salvia hispanica. Journal of Food Safety, 25(1), 9-18. https://doi.org/10.1111/j.0149-6085.2005.25546.x

Anand, P., Kunnumakkara, A. B., Sundaram, C., Tharakan, S. T., Lai, O. S., Sung, B., \& Aggarwal, B. B., (2008). Cancer is a preventable disease that requires lifestyle changes. Pharm Rev., 25(9), 20-25. https://doi.org/10.1007/s11095-008-9690-4

AOAC Official method 994:08 (2000). Aflatoxin in corn, almonds and pistachio nuts, multifunctional column (Mycosep) method. Natural toxins chapter 4 (page 26-27). Official methods of analysis of AOAC international, $17^{\text {th }}$ edition, volume II, AOAC international, Maryland, USA.

Arun, S., Desai, P. S. R., \& Nadkarni, G. B. (2007). A new method for aflatoxin free storage of agricultural commodities. Journal of Food Science, 52(2), 497. https://doi.org/10.1111/j.1365-2621.1987.tb06652.x

Ayerza, R. (2009). The seeds protein and oil content, fatty acid composition and growing cycle length of a single genotype of Chia (Salvia hispanica L.) as affected by environmental factors. Journal of Oleo science, 58(7). https://doi.org/10.5650/jos.58.347

Ayerza, R. (2013). Seed composition of two chia (Salvia hispania L.) genotypes which differs in seed color. Emir Journal of Food Agriculture, 25, 495-550. https://doi.org/10.9755/ejfa.v25i7.13569

Bochicchio, R., Rossi, R., Labelle, R., Bitella, G., Perniola, M., \& Amato, M. (2015). Effect of sowing density and nitrogen top dress fertilization on growth and yield of chia (Salvia hispanica L.) in a Mediterranean Environment: First results. Italian journal of Agronomics, 10(3), 163-166. https://doi.org/10.4081/ija.2015.640

Bullerman, L. (2006). Mycotoxins and food safety. Food Technology, 59-66.

Bukola, C. A., Abiodun, A. O., \& Ukpe, G. P. (2008). Microflora of Chia seeds Sold in Uyo, Eastern Nigeria. World Journal of Agricultural Sciences, 4(3), 346350.

Busillachi, H., Quiroga, M., Bueno, M., Di Sapio, O., Flores, V., \& Severin, C. (2013) Evaluation of Salvia Hispanica cultivated in Santa Fe (Republic of Argentina). Cultivated in Tropics, 34(4), 55-59.

Brunding, G. J. (2008). Biology and Cultivation of Chia Seeds. Academic Press, New York.

Bobek P., Ozdin, O., \& Mikus, M. (1995). Dietary of Chia seeds accelerates cholesterol turnover in hypercholesterolemia rats. Physiological Research Journal, 44(5), 287-291 
Cahill, J. P., \& Provance, M. C. (2004). Genetics of qualitative traits in domesticated chia (Salvia hispanica L.). Journal of Heredity, 93(1), 52-55. https://doi.org/10.1093/jhered/93.1.52

CDC, (2015). Aflatoxicoses outbreak in Kenya -2015: Report to the Ministry of Health, Kenya. Center for Disease Control.

Centers for Disease Control and Prevention (2004). Outbreak of aflatoxin poisoning-eastern and central provinces, Kenya, January-July 2004. MMWR Mortal weekly Rep., 53, 790-793.

Coates, W., \& Ayerza, R. (2006). Production potential of chia in North Western Argentina. Journal of crops production, 5, 229-233. https://doi.org/10.1016/0926-6690(96)89454-4

FAO. (2004). Worldwide regulation for mycotoxins in food and feed in 2003.FAO Food and Nutrition paper 81. Rome: Food and Agriculture Organization of the United Nations. Retrieved from http://www.fao.org/docrep/007/y5499e/y5499e00.htm

JEFCA (Joint FAO/WHO Expert committee on food additives) (2008). In sixty-eight meeting, 19-28 June, Geneva

Ludwig, T., Worsch, S., Heikenwalder, M., Daniel, H., Hauner, H., \& Bader, B. L. (2013). Metabolic and immunomodulatory effects on n-3 fatty acids are different in mesenteric epididymal adipose tissue of diet-induced obese mice. American journal of physiology in endocrinal metabolism, 304(11), 1140-1156. https://doi.org/10.1152/ajpendo.00171.2012

Menga, V., Amato, M., Phillips, T. D., Angelino, D., Morreale, F., \& Fares, C. (2017). Gluten-free pasta incorporating chia (Salvia hispanica L.) as thickening agent: An approach to naturally improve the nutritional profile and the in vitro carbohydrate digestibility. Journal of Chemistry, 221, 1954-1961. https://doi.org/10.1016/j.foodchem.2016.11.151

Perrone, G., Susca, A., Cozz, G., Ehrlich, K., Varga, J., Frisvad, J. C., ... Samson, R. A., (2007). Biodiversity of Aspergillus species in some important agricultural products. Study of Mycology, 59, 53-66. https://doi.org/10.3114/sim.2007.59.07

Proctor, R. H. (2009). Evidence that a secondary metabolic biosynthetic gene cluster has grown by gene relocation during evolution of the filamentous fungus Fusarium. Molecular Microbiology. Malden, 74(5), 1128-1142. https://doi.org/10.1111/j.1365-2958.2009.06927.x

Rifai, M. A. (1969). A revision of the Genus Trichoderma. Mycology Paper, 116, 1-56.

Samson, R. A., Visagie, C. M., Houbraken, J., Hong S. B., Hubka, V., Klaassen, C. H. W., Perrone, G. ... Frisvad, J. C. (2014). Phylogeny, identification and nomenclature of the genus Aspergillus. Studies in Mycology, 78, 141-173. https://doi.org/10.1016/j.simyco.2014.07.004

Yao, W., Li, J., Wang, J. J., Zhou, W., Wang, Q., Zhu, R., Wang, F., \& Thacker, P. (2012). Effects of dietary ratio of n-6 to n-3 polyunsaturated fatty acid on immunoglobulins, cytokines, fatty acids compositions and performance of lactating sows and suckling piglet. Journal of animal science and biotechnology, 3(1), 43-50. https://doi.org/10.1186/2049-1891-3-43

\section{Copyrights}

Copyright for this article is retained by the author(s), with first publication rights granted to the journal.

This is an open-access article distributed under the terms and conditions of the Creative Commons Attribution license (http://creativecommons.org/licenses/by/4.0/). 